\title{
Antinociceptive and Anxiolytic-Like Effects of Some Compounds Carrying Benzothiazole Ring
}

\author{
Ümide DEMİR ÖZKAY*, Umut İrfan ÜÇEL, Nazlı TURAN YÜCEL, Özgür Devrim CAN \\ Anadolu University, Faculty of Pharmacy, Department of Pharmacology, 26470, Eskisehir, Turkey
}

\begin{abstract}
The aim of this study was to examine the antinociceptive and anxiolytic-like effects of some compounds carrying benzothiazole ring. The antinociceptive effects of test compounds, administrated at a dose of $40 \mathrm{mg} / \mathrm{kg}$, were investigated by tail clip, hot plate and acetic acid-induced writhing tests. Hole board and elevated plus maze tests were performed to evaluate the anxiolytic-like effects of the compounds. Rota-rod device was used to assess the motor coordinations of mice. As a result of the experiments, it was determined that compounds $3 \mathrm{f}, 3 \mathrm{~g}$ and $3 \mathrm{~h}$ increased the reaction times of animals in the tail clip and hot plate tests, and compound $3 \mathrm{e}$ reduced the writhing number of mice in the acetic acid-induced writhing test. On the other hand, in the hole board test, compounds 3f, $3 \mathrm{~g}$ and $3 \mathrm{~h}$ reduced the first head-dipping latencies of mice while increasing the total number of head-dips. In the elevated plus maze test, it has been shown that the same derivatives increase the percentages of open arm entries and time spent in the open arms. In the Rota-rod tests, test compounds did not change the falling time of mice from the rotating mill. All these findings point out that compounds $3 \mathrm{f}, 3 \mathrm{~g}$ and $3 \mathrm{~h}$ exhibit central antinociceptive and anxiolytic-like effects and compound $3 e$ shows a peripheral antinociceptive effect.
\end{abstract}

Keywords: Benzothiazole ring, antinociceptive, anxiolytic, Rota-rod

\section{Benzotiyazol Halkası Taşıyan Bazı Bileşiklerin Antinosiseptif ve Anksiyolitik-Benzeri Etkileri}

ÖZ

Bu çalışmanın amacı benzotiyazol halkası taşıyan bazı bileşiklerin antinosiseptif ve anksiyolitik-benzeri etkilerinin incelenmesidir. $40 \mathrm{mg} / \mathrm{kg}$ dozda uygulanan test bileşiklerinin antinosiseptif etkileri kuyruk sıkıştırma, sıcak plaka ve asetik asid ile indüklenen kıvranma testleri ile araştırılmıştır. Bileşiklerin anksiyolitik-benzeri etkilerini incelemek için delikli tahta ve yükseltilmiş artı labirent testleri gerçekleştirilmiştir. Farelerin motor koordinasyonlarını değerlendirmek üzere Rota-rod cihazı kullanılmıştır. Deneyler sonucunda $3 \mathrm{f}, 3 \mathrm{~g}$ ve $3 \mathrm{~h}$ kodlu bileşiklerin kuyruk sıkıştırma ve sıcak plaka testlerinde hayvanların reaksiyon sürelerini artırdığı ve 3e kodlu bileşiğin ise asetik asid ile indüklenen kıvranma testinde farelerin kıvranma sayılarını azalttı̆̆ belirlenmiştir. Diğer yandan, $3 \mathrm{f}, 3 \mathrm{~g}$ ve $3 \mathrm{~h}$ kodlu bileşikler delikli tahta testinde farelerin ilk baş daldırma sürelerini kısaltırken toplam baş daldırma sayılarını artırmıstır. Yükseltilmiş artı labirent testinde ise aynı türevlerin farelerin açık kola giriş sayılarının ve açık kolda kalma sürelerinin yüzdelerini artırdığı ortaya konulmuştur. Rota-rod testlerinde test bileşikleri farelerin dönen milden düşme sürelerini değiştirmemiştir. Tüm bu bulgular, $3 \mathrm{f}, 3 \mathrm{~g}$ ve $3 \mathrm{~h}$ kodlu bileşiklerin santral antinosiseptif ve anksiyolitik-benzeri etki gösterdiklerine; 3e kodlu bileşiğin ise periferal antinosiseptif etki gösterdiğine işaret etmektedir.

Anahtar Kelimeler: Benzotiyazol halkası, antinosiseptif, anksiyolitik, Rota-rod

To cite this article: Demir Özkay Ü. Üçel U.I. Turan Yücel N. Can Ö.D. Antinociceptive and Anxiolytic-Like Effects of Some Compounds Carrying Benzotbiazole Ring. Kocatepe Vet J. (2019) 12(2):122-129.

Submission: 08.02.2019 Accepted: 13.03.2019 Published Online: 10.04.2019

ORCID ID; ÜDÖ: 0000-0002-6773-4266, Uİ̈: 0000-0002-5470-0139, NTY: 0000-0002-0371-2703,

ÖDC: 0000-0002-2260-3174

*Corresponding author e-mail: udemir@anadolu.edu.tr 


\section{GİRİ̧̧}

Benzotiyazol, benzen ve tiyazolün kondenzasyonu sonucunda oluşan bisiklik heterosiklik bir halkadır (Hroch ve ark. 2015). Benzotiyazol halka sistemi ilaç geliştirme çalışmalarında kullanılan önemli yapılardan biridir. Yapısında bu halkayı taşıyan çeşitli bileşiklerin antibakteriyel (Singh ve ark. 2013, Thakkar ve ark. 2017, Zha ve ark. 2017), antifungal (Singh ve ark. 2013, Zha ve ark. 2017), antimalaryal (Sarkar ve ark. 2016, Thakkar ve ark. 2017), antiastmatik (Costanzo ve ark. 2003), antikanser (Aouad ve ark. 2018, Osmaniye ve ark. 2018), antiinflamatuar (Muttu ve ark. 2010, Ugwu ve ark. 2018), antidiyabetik (MorenoDíaz ve ark. 2008, Mariappan ve ark. 2012) ve antioksidan (Karali ve ark. 2010) gibi etkileri bildirilmiştir.

Benzotiyazol türevi çeşitli bileşiklerin santral sinir sistemi (SSS) ile ilişkili farmakolojik aktiviteleri de rapor edilmiştir. $\mathrm{Bu}$ halkayı taşıyan bileşiklerin antikonvülzan (Siddiqui ve ark. 2007, Amnerkar ve Bhusari 2010, Hassan ve ark. 2012, Ali ve Siddiqui 2015, Liu ve ark. 2016), antinosiseptif (Gökce ve ark. 2001, Siddiqui ve ark. 2008, Azam ve ark. 2013, Hamdy ve ark. 2013), antidepresan-benzeri (Siddiqui ve ark. 2008, Wang ve ark. 2014), anksiyolitik-benzeri (Sasaki-Hamada ve ark. 2013), nöroprotektif (Carboni ve ark. 2004, Anzini ve ark. 2010, Hassan ve ark. 2012) ve anti-Alzheimer (Keri ve ark. 2013, Demir Özkay ve ark. 2017a) gibi aktiviteleri olduğu bildirilmiştir.

Benzotiyazol halkası taşıyan bileşiklerin SSS üzerine potansiyel farmakolojik etkilerinden hareketle, bu çalışmada Anadolu Üniversitesi Eczacılık Fakültesi Farmasötik Kimya Anabilim Dalı tarafindan sentezlenen ve daha önce antidepresan-benzeri etkinlikleri bildirilmiş olan (Demir Özkay ve ark. 2017b) benzotiyazol türevi bazı bileşiklerin olası antinosiseptif ve anksiyolitik-benzeri etkinlikleri araştırılmışıtır.

\section{MATERYAL ve METOT}

\section{Bileşiklerin Sentezi}

Benzotiyazol türevleri, 2-kloro-N-(5,6dimetilbenzotiyazol-2-il)asetamid bileşiği ile çeşitli siklik aminlerin potasyum karbonat varliğında aseton içerisinde reaksiyonu sonucunda elde edilmiştir. Bileşiklerin sentez prosedürü ve spektral verileri çalışma grubumuz tarafından rapor edilmiştir (Demir Özkay ve ark. 2017b). Test bileşiklerinin kimyasal yapıları Tablo 1'de sunulmuştur.

\section{Deney Hayvanlar1}

Deneyler BALB/c fareler (30-35 g) ile gerçekleştirilmiştir. Deney hayvanları $24 \pm 1^{\circ} \mathrm{C}$ sicaklıktaki iyi havalandırılan ve 12 saat aydınlık/12 saat karanlık döngüsüne sahip odalarda barındırılmıştır. Deney hayvanları deneylere başlanmadan en az 48 saat önce laboratuvara getirilmiştir. Deneyler sırasında laboratuvarın sıcaklı̆ğ, ses düzeyi ve aydınlatma koşulları sabit tutulmuştur. $\mathrm{Bu}$ çalışmanın deneysel protokolü, Anadolu Üniversitesi Hayvan Deneyleri Yerel Etik Kurulu tarafindan onaylanmıştır.

Tablo 1. Test bileşiklerinin kimyasal yapıları Table 1. Chemical structures of test compounds

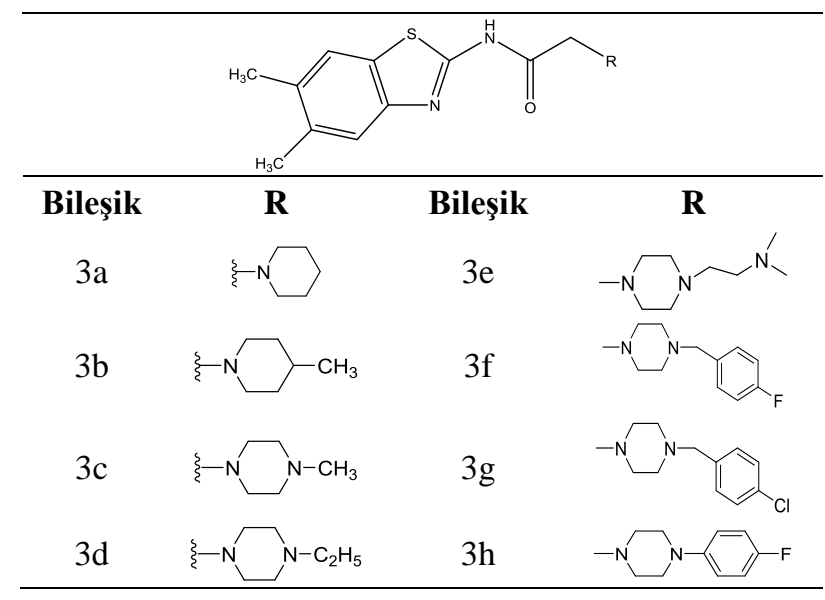

\section{Test Maddelerinin Uygulanması}

Deneyler için test bileşikleri $40 \mathrm{mg} / \mathrm{kg}$ dozda oral yolla uygulanmıştır (Wang ve ark. 2014). Test bileşikleri çiçek yağı içerisinde çözüldügü için kontrol grubunda yer alan farelere aynı hacimde çiçek yağı uygulanmıştır. Referans ilaç olarak morfin sülfat (10 $\mathrm{mg} / \mathrm{kg}$, i.p) (Kaplancikli ve ark. 2009) ve diazepam (1 $\mathrm{mg} / \mathrm{kg}$, i.p) (Can ve ark. 2016) kullanılmıştır.

\section{Analjezi Testleri}

\section{Kuyruk Sıkıştırma Testi}

Kuyruk sıkıştırma testi, deney hayvanlarının mekanik ağrllı uyarana verdikleri yanıtı değerlendirmek için uygulanan bir testtir. Bu test, kuyruklarına metal bir klamp takılan deney hayvanlarının dönüp klampi ısırma sürelerinin ölçülmesi esasına dayanmaktadır. Deneylerden önce farelere duyarllilk testi uygulanmıştır. Bu testlerde klampe 10 saniyeden kısa sürede yanıt veren fareler deneylere alınmıştır. Farelerin kuyruklarının hasar görmemesi için uyar1 10 saniyeden fazla uygulanmamıştır (D'Amour ve Smith 1941, Demir Özkay ve Can 2013).

\section{Sicak Plaka Testi}

Sıcak plaka testi, deney hayvanlarının termal ağrnlı uyarana verdikleri yanıtı değerlendirmek için uygulanan bir testtir. Bu test, $55 \pm 1.0^{\circ} \mathrm{C}$ 'ye ayarlanmış Hot-plate cihazına (Ugo Basile, No. 7280, İtalya) konulan farelerin ayaklarını yalamaya başlama ve/veya zıplama sürelerinin kaydedilmesi esasına dayanmaktadır. Deneylerden önce farelere duyarlılık testi uygulanmış ve 15 saniyeden kısa sürede yanıt veren fareler deneylere alınmıştır. Uyarı 30 saniyeden 
fazla uygulanmamıştır (Woolfe ve MacDonald 1944, Demir Özkay ve Can 2013).

Kuyruk sikıştırma ve sicak plaka testlerinde ölçülen yanıt sürelerinden maksimum olası etkinin yüzdesini (\%MPE) hesaplamak için aşağıdaki formül kullanılmıştır:

\%MPE $=\frac{\text { (uygulama sonrasi süre }- \text { uygulama öncesi süre) }}{\text { (cut }- \text { off süresi }- \text { uygulama öncesi süre })} \times 100$

\section{Asetik asid ile İndüklenen Kıvranma Testi}

Asetik asid ile indüklenen kivranma testi, deney hayvanlarının kimyasal ağrılı uyarana verdikleri yanıtı değerlendirmek için uygulanan bir testtir. Bu testte intraperitonal yolla uygulanan \%0.6'lk asetik asid solüsyonu $(10 \mathrm{~mL} / \mathrm{kg})$ farelerde abdominal ağrı ve kıvranma yanıtı oluşturmaktadır. Test, asetik asid enjeksiyonundan 5 dakika sonra deney hayvanlarının kıvranma davranışlarının 10 dakika süre ile sayılması esasına dayanmaktadır (Koster ve ark. 1959, Demir Özkay ve Can 2013).

\section{Davranış Deneyleri \\ Delikli Tahta Testi}

Farelerin keşif davranışları delikli tahta testi ile değerlendirilmiştir. Testin yapıldığı delikli tahta cihazı (Ugo Basile, No. 6650, Varese, İtalya) $3 \mathrm{~cm}$ çapında 16 adet deliğin bulunduğu gri pleksiglas bir panelden $(40 \times 40 \mathrm{~cm})$ oluşmaktadır. Cihaz yerden $15 \mathrm{~cm}$ yüksekliktedir. Delikli tahta testinde, her bir fare sırtı gözlemciye dönük biçimde cihazın ortasına konulmuş ve cihazı serbestçe keşfetmesine izin verilmiştir. Farelerin ilk baş daldırma süreleri ve toplam baş daldırma sayıları 5 dakikalık süre boyunca kaydedilmiştir (Takeda ve ark. 1998, Can ve ark. 2012a).

\section{Yükseltilmiş Artı Şekilli Labirent Testi}

Farelerin anksiyete şiddetleri yükseltilmiş artı şekilli labirent testleri ile değerlendirilmiştir. İki açık kol $(35 \times 5 \mathrm{~cm})$ ve iki kapalı koldan $(35 \times 5 \times 15 \mathrm{~cm})$ oluşan yükseltilmiş artı şekilli labirent düzeneği (Ugo Basile, No. 40143, Varese, Italya) yerden $60 \mathrm{~cm}$ yüksekliktedir. Bu testte, her bir fare yüzü açık kola dönük şekilde merkez platforma yerleştirilmiş ve 5 dakikalık süre boyunca farelerin açık ve kapalı kollara giriş sayıları ve bu kollarda geçirdikleri süreler kaydedilmiştir (Can ve ark. 2012b, Can ve ark. 2013).

Deney hayvanlarının açık kola giriş sayılarının yüzdesini (\%AKGS) ve açık kolda kaldıkları sürelerin yüzdesini (\%AKKS) hesaplamak için aşağıdaki formüller kullanılmıştır:

$$
\% \text { AKGS }=\frac{\text { Açık kola giriş sayısı }}{\text { Açı ve kapalı kollara giriş sayısı }} \times 100
$$

\section{$\%$ AKKS $=\frac{\text { Açık kolda geçirilen süre }}{\text { Açı ve kapalı kollara geçirilen süre }} x 100$ Rota-rod Testi}

Farelerin motor koordinasyonlar1 Rota-rod testleri ile değerlendirilmiştir. Deneyler başlamadan önce farelere $16 \mathrm{rpm}$ sabit hızda dönen Rota-rod cihazı (Ugo Basile, no.47600, Varese, İtalya) ile üç ardişık gün boyunca alıştırma (training) yapılmıştır. Dönen milin üzerinde 180 saniyeden daha fazla kalabilen fareler deneylere alınmıştır. Farelerin dönen milin üzerinden düşme süreleri cihaz tarafindan kaydedilmiştir (Kaplancikli ve ark. 2009, Demir Özkay ve Can 2013).

\section{İstatistiksel Analiz}

İstatistiksel analiz için Graphpad Prism ver. 6.01 paket programı kullanılmıştır. Deneylerden elde edilen veriler tek yönlü varyans analizi (ANOVA) ve ardından Tukey HSD çoklu karşılaştırma testleri uygulanarak değerlendirilmiştir. Sonuçlar, ortalama \pm ortalamanın standart hatası olarak verilmiştir. $\mathrm{p}<0.05$ değeri anlamlı kabul edilmiştir.

\section{BULGULAR}

Analjezi Deneylerine İlişkin Bulgular Kuyruk sıkıştırma testine ilişkin bulgular

Test bileşikleri ve morfin uygulamalarının kuyruk sıkıştırma testinde farelerin reaksiyon süreleri üzerine etkileri Şekil 1'de verilmiştir $\quad[\mathrm{F}(9,60)=11.77$, $\mathrm{p}<0.001]$. Tek yönlü ANOVA testini takiben uygulanan çoklu karşılaştırma testleri, 3f, $3 \mathrm{~g}$ ve $3 \mathrm{~h}$ kodlu türevlerin hayvanların $\% \mathrm{MPE}$ değerlerini kontrol grubunun \%MPE değerlerine göre istatistiksel olarak anlamlı biçimde artırdığını, 3a-3e kodlu türevlerin ise etkisiz olduğunu ortaya koymuştur. Referans ilaç morfin uygulamaları da farelerin \%MPE değerlerini anlamlı biçimde artırmıştır (Şekil 1).

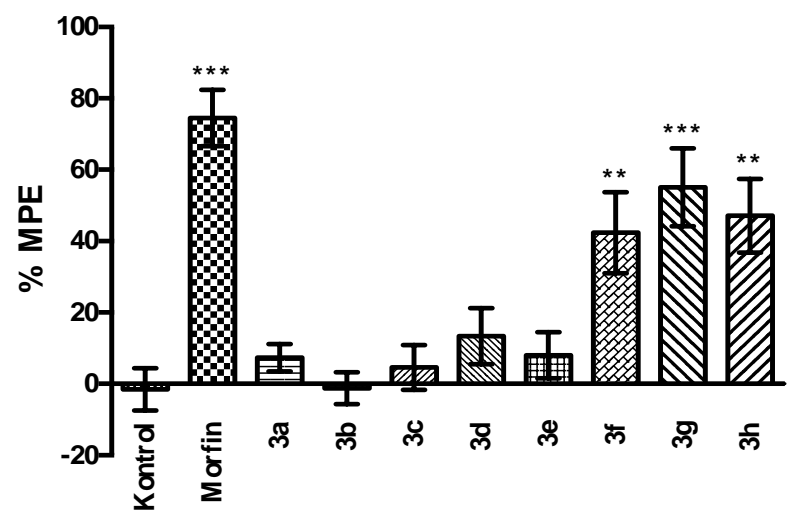

Şekil 1. Test bileşiklerinin (40 mg/kg) ve morfin'in (10 $\mathrm{mg} / \mathrm{kg}$ ) kuyruk sıkıştırma testinde farelerin \%MPE değerleri üzerine etkileri. Kontrol grubuna göre anlamlı farklılık ${ }^{* *} \mathrm{p}<0.01,{ }^{* * *} \mathrm{p}<0.001$. Tek yönlü varyans analizi, takiben Tukey HSD çoklu karşılaştırma testi, $n=7$.

Figure 1. Effects of test compounds $(40 \mathrm{mg} / \mathrm{kg})$ and morphine $(10 \mathrm{mg} / \mathrm{kg})$ on MPE \% values of mice in the tail clip test. Significance against control group ${ }^{* *} \mathrm{p}<0.01$, ${ }^{* * *} \mathrm{p}<0.001$. One-way ANOVA, post hoc Tukey's test, $\mathrm{n}=7$. 


\section{Sicak plaka testine ilişkin bulgular}

Şekil 2'de test bileşikleri ve morfin uygulamalarının sicak plaka testinde farelerin reaksiyon süreleri üzerine etkileri gösterilmiştir $[\mathrm{F}(9,60)=11.20, \mathrm{p}<0.001]$. Tek yönlü ANOVA testini takiben uygulanan çoklu karşılaştırma testleri, $3 \mathrm{f}, 3 \mathrm{~g}$ ve $3 \mathrm{~h}$ kodlu türevlerin ve referans ilaç morfin'in hayvanların \%MPE değerlerini kontrol grubunun \%MPE değerlerine göre istatistiksel olarak anlamlı biçimde artırdığını ortaya koymuştur. 3a-3e kodlu türevlerin farelerin \%MPE değerlerinde anlamlı bir değişikliğe neden olmadığı belirlenmiştir (Şekil 2).

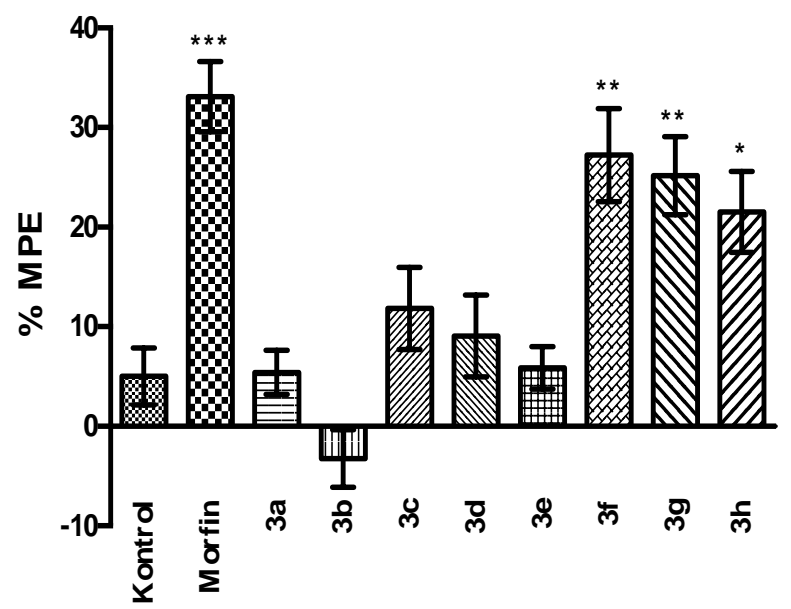

Şekil 2. Test bileşiklerinin $(40 \mathrm{mg} / \mathrm{kg})$ ve morfin'in $(10 \mathrm{mg} / \mathrm{kg})$ sicak plaka testinde farelerin \%MPE değerleri üzerine etkileri. Kontrol grubuna göre anlaml1 farkl11.k ${ }^{*} \mathrm{p}<0.05,{ }^{* *} \mathrm{p}<0.01,{ }^{* *} \mathrm{p}<0.001$. Tek yönlü varyans analizi, takiben Tukey HSD çoklu karşılaştırma testi, $n=7$.

Figure 2. Effects of test compounds $(40 \mathrm{mg} / \mathrm{kg}$ ) and morphine $(10 \mathrm{mg} / \mathrm{kg})$ on MPE \% values of mice in the hot plate test. Significance against control group ${ }^{*} \mathrm{p}<0.05,{ }^{* *} \mathrm{p}<0.01,{ }^{* *} \mathrm{p}<0.001$. One-way ANOVA, post hoc Tukey's test, $\mathrm{n}=7$.

Asetik asid ile indüklenen kıvranma testine ilişkin bulgular

Test bileşikleri ve morfin uygulamalarının asetik asid ile indüklenen kıvranma testinde farelerin kıvranma sayıları üzerine etkileri Şekil 3'de verilmiştir $[\mathrm{F}(9,60)=12.51, \mathrm{p}<0.001]$.

Tek yönlü ANOVA testini takiben uygulanan çoklu karşılaştırma testleri, 3e kodlu türevin hayvanların kıvranma sayılarını kontrol grubunun kivranma sayılarına göre anlamlı biçimde azalttığını, 3a-3d ve $3 \mathrm{f}$ $3 \mathrm{~h}$ kodlu türevlerin ise etkisiz olduğunu ortaya koymuştur. Referans ilaç morfin uygulamaları da farelerin kıvranma sayılarını anlamlı biçimde azaltmıştır (Şekil 3).

\section{Davranış Deneylerine İlişkin Bulgular Delikli tahta testine ilişkin bulgular}

Şekil 4'de test bileşikleri ve diazepam uygulamalarının delikli tahta testinde farelerin ilk baş daldırma süreleri üzerine etkileri gösterilmiştir $[\mathrm{F}(9,60)=5.84, \mathrm{p}<0.001]$.
Tek yönlü ANOVA testini takiben uygulanan çoklu karşılaştırma testleri, $3 \mathrm{f}, 3 \mathrm{~g}$ ve $3 \mathrm{~h}$ kodlu türevlerin ve referans ilaç diazepam'ın hayvanların ilk baş daldırma sürelerini kontrol grubunun ilk baş daldırma sürelerine göre istatistiksel olarak anlamlı biçimde kısalttığını ortaya koymuştur. 3a-3e kodlu türevlerin farelerin ilk baş daldırma sürelerinde anlamlı bir değişikliğe neden olmadığı belirlenmiştir (Şekil 4).

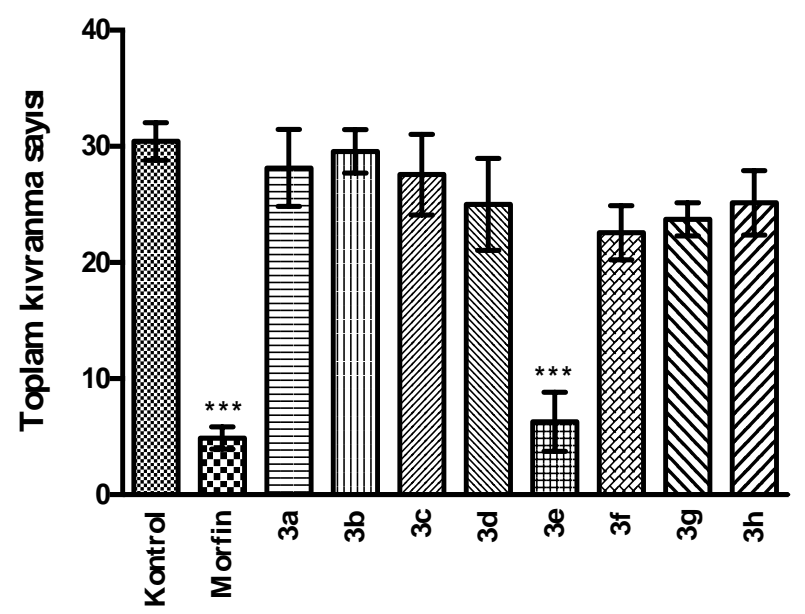

Şekil 3. Test bileşiklerinin ( $40 \mathrm{mg} / \mathrm{kg}$ ) ve morfin'in $(10 \mathrm{mg} / \mathrm{kg}$ ) asetik asid ile indüklenen kivranma testinde farelerin kıvranma sayıları üzerine etkileri. Kontrol grubuna göre anlamlı farkl11lk ${ }^{* * *} \mathrm{p}<0.001$. Tek yönlü varyans analizi, takiben Tukey HSD çoklu karşılaştırma testi, $\mathrm{n}=7$.

Figure 3. Effects of test compounds $(40 \mathrm{mg} / \mathrm{kg})$ and morphine $(10 \mathrm{mg} / \mathrm{kg})$ on writhing number of mice in the acetic acid-induced writhing test. Significance against control group ${ }^{* * *} \mathrm{p}<0.001$. One-way ANOVA, post hoc Tukey's test, $n=7$.

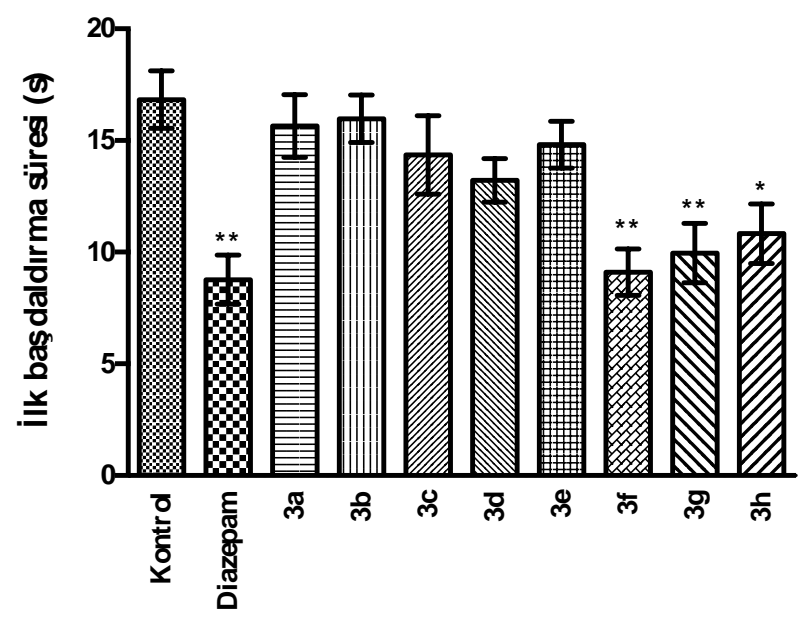

Şekil 4. Test bileşiklerinin $(40 \mathrm{mg} / \mathrm{kg})$ ve diazepam'ın (1 $\mathrm{mg} / \mathrm{kg}$ ) delikli tahta testinde farelerin ilk baş daldırma süreleri üzerine etkileri. Kontrol grubuna göre anlamlı farklilık ${ }^{*} \mathrm{p}<0.05,{ }^{* *} \mathrm{p}<0.01$. Tek yönlü varyans analizi, takiben Tukey HSD çoklu karşılaştırma testi, $\mathrm{n}=7$.

Figure 4. Effects of test compounds $(40 \mathrm{mg} / \mathrm{kg}$ ) and diazepam $(1 \mathrm{mg} / \mathrm{kg})$ on first head-dipping latencies of mice in the hole board test. Significance against control group ${ }^{*} \mathrm{p}<0.05,{ }^{* *} \mathrm{p}<0.01$. One-way ANOVA, post hoc Tukey's test, $\mathrm{n}=7$. 
Test bileşikleri ve diazepam uygulamalarının delikli tahta testinde farelerin toplam baş daldırma sayıları üzerine etkileri Şekil 5'de verilmiştir $[\mathrm{F}(9,60)=17.19$, $\mathrm{p}<0.001]$. Tek yönlü ANOVA testini takiben uygulanan çoklu karşılaştırma testleri, 3f, 3g ve $3 \mathrm{~h}$ kodlu türevlerin hayvanların toplam baş daldırma sayılarını kontrol grubunun toplam baş daldırma sayılarına göre anlamlı biçimde artırdığını, 3a-3e kodlu türevlerin ise etkisiz olduğunu ortaya koymuştur. Referans ilaç diazepam uygulamaları da farelerin toplam baş daldırma sayılarını anlamlı biçimde artırmıştır (Şekil 5).

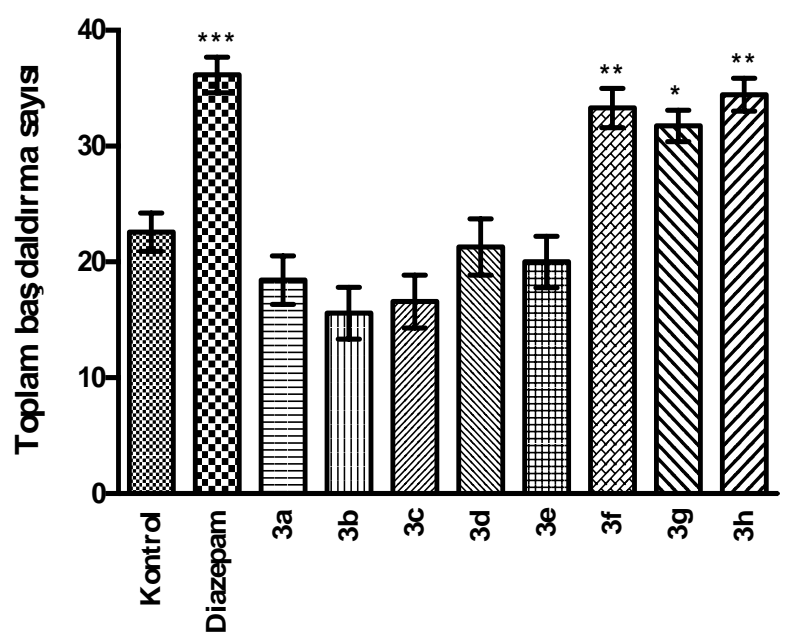

Şekil 5. Test bileşiklerinin (40 mg/kg) ve diazepam'ın (1 mg/kg) delikli tahta testinde farelerin toplam baş daldırma sayıları üzerine etkileri. Kontrol grubuna göre anlamlı farkl1lik ${ }^{*} \mathrm{p}<0.05,{ }^{* *} \mathrm{p}<0.01,{ }^{* *} \mathrm{p}<0.001$. Tek yönlü varyans analizi, takiben Tukey HSD çoklu karşılaştırma testi, $n=7$.

Figure 5. Effects of test compounds (40 mg/kg) and diazepam $(1 \mathrm{mg} / \mathrm{kg})$ on total number of head-dips of mice in the hole board test. Significance against control group ${ }^{*} \mathrm{p}<0.05,{ }^{* *} \mathrm{p}<0.01,{ }^{* *} \mathrm{p}<0.001$. Oneway ANOVA, post hoc Tukey's test, $n=7$.

Yükseltilmiş artı şekilli labirent testine ilişkin bulgular

Şekil 6'da test bileşikleri ve diazepam uygulamalarının yükseltilmiş artı şekilli labirent testinde farelerin \%AKGS değerleri üzerine etkileri gösterilmiştir $[\mathrm{F}(9,60)=5.96, \mathrm{p}<0.001]$.

Tek yönlü ANOVA testini takiben uygulanan çoklu karş1laştırma testleri, 3f, $3 \mathrm{~g}$ ve $3 \mathrm{~h}$ kodlu türevlerin ve referans ilaç diazepam'in hayvanların \%AKGS değerlerini kontrol grubunun \%AKGS değerlerine göre istatistiksel olarak anlamlı biçimde artırdı̆̆ını ortaya koymuştur. 3a-3e kodlu türevlerin farelerin \%AKGS değerlerinde anlamlı bir değişikliğe neden olmadığı belirlenmiştir (Şekil 6).

Test bileşikleri ve diazepam uygulamalarının yükseltilmiş artı şekilli labirent testinde farelerin \%AKKS değerleri üzerine etkileri Şekil 7'de verilmiştir $[\mathrm{F}(9,60)=12.81, \quad \mathrm{p}<0.001]$. Tek yönlü ANOVA testini takiben uygulanan çoklu karşılaştırma testleri, 3f, $3 \mathrm{~g}$ ve $3 \mathrm{~h}$ kodlu türevlerin hayvanların $\%$ AKKS değerlerini kontrol grubunun \%AKKS değerlerine göre anlamlı biçimde artırdığını, 3a-3e kodlu türevlerin ise etkisiz olduğunu ortaya koymuştur. Referans ilaç diazepam uygulamaları da farelerin \%AKKS değerlerini anlamlı biçimde artırmıştır (Şekil 7).

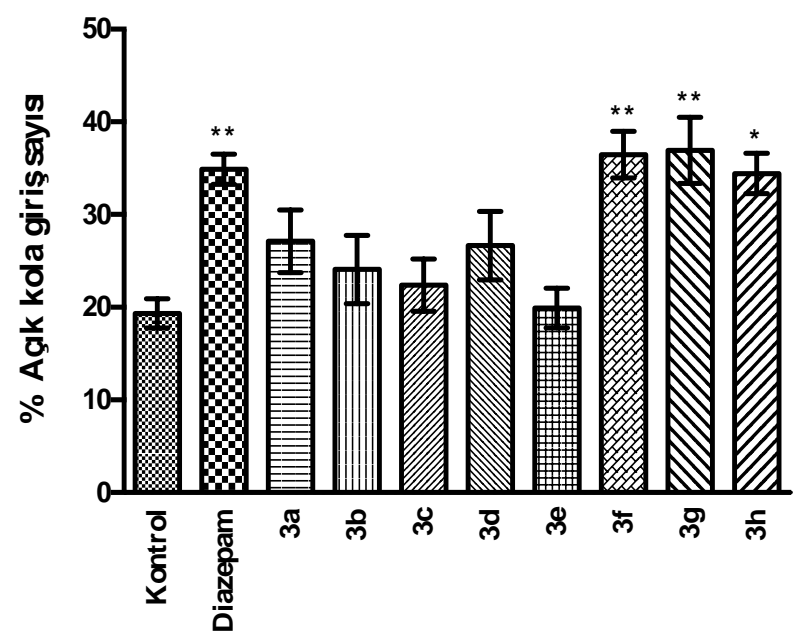

Şekil 6. Test bileşiklerinin (40 mg/kg) ve diazepam'in (1 mg/kg) yükseltilmiş artı şekilli labirent testinde farelerin açık kola giriş sayılarının yüzdeleri üzerine etkileri. Kontrol grubuna göre anlamlı farklilik ${ }^{*} \mathrm{p}<0.05,{ }^{* *} \mathrm{p}<0.01$. Tek yönlü varyans analizi, takiben Tukey HSD çoklu karşılaştırma testi, $\mathrm{n}=7$.

Figure 6. Effects of test compounds (40 mg/kg) and diazepam $(1 \mathrm{mg} / \mathrm{kg})$ on percentages of open arm entries of mice in the elevated plus maze test. Significance against control group ${ }^{*} \mathrm{p}<0.05,{ }^{* *} \mathrm{p}<0.01$. One-way ANOVA, post hoc Tukey's test, $\mathrm{n}=7$.

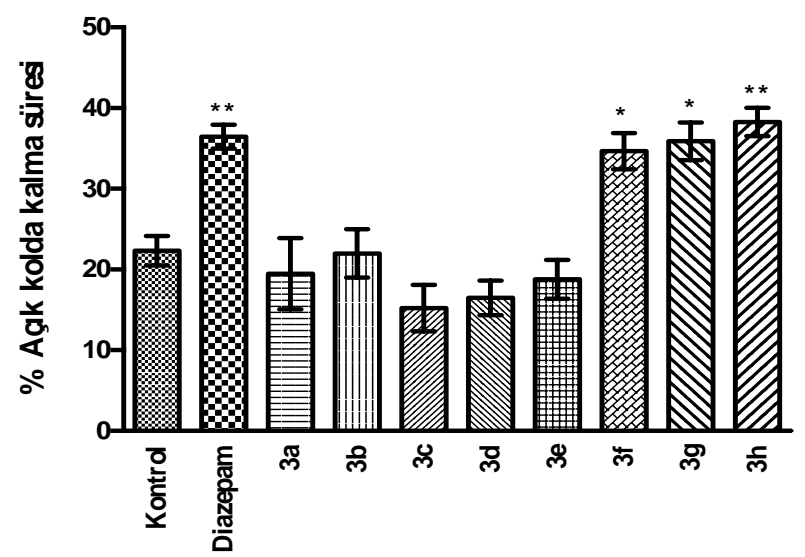

Şekil 7. Test bileşiklerinin (40 mg/kg) ve diazepam'ın (1 $\mathrm{mg} / \mathrm{kg}$ ) yükseltilmiş artı şekilli labirent testinde farelerin açık kolda geçirdikleri sürelerin yüzdeleri üzerine etkileri. Kontrol grubuna göre anlamlı farklılık ${ }^{*} \mathrm{p}<0.05,{ }^{* *} \mathrm{p}<0.01$. Tek yönlü varyans analizi, takiben Tukey HSD çoklu karşılaştırma testi, $n=7$.

Figure 7. Effects of test compounds $(40 \mathrm{mg} / \mathrm{kg}$ ) and diazepam $(1 \mathrm{mg} / \mathrm{kg})$ on percentages of time spent by mice in open arms in the elevated plus maze test. Significance against control group ${ }^{*} \mathrm{p}<0.05,{ }^{* *} \mathrm{p}<0.01$. One-way ANOVA, post hoc Tukey's test, $\mathrm{n}=7$. 


\section{Rota-rod Testine İlişkin Bulgular}

Test bileșiklerinin farelerin dönen milden düşme sürelerinde istatistiksel olarak anlamlı bir değişikliğe neden olmadığı görülmüştür (veri gösterilmedi).

\section{TARTIŞMA}

$\mathrm{Bu}$ çalışmada, benzotiyazol türevi bazı bileşiklerin olas1 antinosiseptif ve anksiyolitik-benzeri etkileri araştırılmıştır. Bileşiklerin antinosiseptif etkilerini değerlendirmek için kuyruk sıkıştırma, sıcak plaka ve asetik asid ile indüklenen kıvranma testleri yapılmıştır. Anksiyolitik-benzeri etkileri delikli tahta ve yükseltilmiş artı şekilli labirent testleri ile araştırılmışır. Test bileşiklerinin farelerin motor koordinasyonlar1 üzerine olas1 etkileri Rota-rod testi ile değerlendirilmiştir.

Kuyruk sıkıştırma ve sıcak plaka testleri santral antinosiseptif etkinliğin araştırılmasında sıklkkla kullanilan testlerdir (Can ve ark. 2012a, Demir Özkay ve Can 2013). Bu çalışmada, kuyruk sıkıştırma ve sicak plaka testlerinde $3 \mathrm{f}$, $3 \mathrm{~g}$ ve $3 \mathrm{~h}$ kodlu test bileşiklerinin uygulanması ile farelerin yanıt sürelerinin uzadığ1 belirlenmiştir. Bu bulgular, söz konusu türevlerin santral antinosiseptif etkinlik gösterdiklerini ortaya koymuştur. Kuyruk sıkıştırma testinin ağırlıklı olarak spinal düzeydeki nosiseptif iletim ile, sicak plaka testinin ise daha ziyade supraspinal düzeydeki nosiseptif iletim ile ilişkili olduğu bildirilmiştir (Wong ve ark. 1994, Gabra ve Sirois 2003). Bu nedenle, 3f, $3 \mathrm{~g}$ ve $3 \mathrm{~h}$ kodlu test bileşiklerinin antinosiseptif etkilerinin hem spinal hem de supraspinal mekanizmalar ile ilişkili olduğu ileri sürülebilir. Diğer yandan $3 \mathrm{f}, 3 \mathrm{~g}$ ve $3 \mathrm{~h}$ kodlu test bileşiklerinin sırasiyla mekanik ve termal ağrllı uyaran uygulanan kuyruk sıkıştırma ve sıcak plaka testlerinde antinosiseptif etki göstermeleri, söz konusu türevlerin hem mekanik hem de termal ağrilı uyaranın taşındığı nöronal yolakları etkilediğini işaret etmektedir.

Asetik asid ile indüklenen kıvranma testi periferal antinosiseptif etki tarama çalışmalarında sıklıkla kullanılan bir testtir (Kaplancikli ve ark. 2009, Demir Özkay ve Can 2013). Bu testte intraperitonal asetik asid uygulamas1, deney hayvanlarında abdominal kasların kasılması, arka bacakların ekstansiyonu ve bedenin uzaması ile karakterize bir reaksiyona neden olmaktadır (Park ve ark. 2012). İntraperitonal irritasyonun asetilkolin, P maddesi, histamin, kininler ve prostaglandinler gibi çeşitli endojen maddelerin salınımını tetiklediği bildirilmiştir. $\mathrm{Bu}$ endojen maddelerin vasküler permeabiliteyi artırdıkları, nosisepsiyon eşiğini düşürdükleri ve nonsteroidal antiinflamatuar ilaçlara ve/veya opioid ilaçlara duyarlı nosiseptif nöronları stimüle ettikleri rapor edilmiştir (Coelho ve ark. 2005, Pinheiro ve ark. 2012). Bu çalışmada, 3e kodlu bileşiğin farelerin asetik asid ile indüklenen kıvranma sayılarını azalttı̆̆ belirlenmiştir. Söz konusu periferal antinosiseptif etkinin, test maddesinin periferik dokulardaki inflamatuar mediyatörlerin salıverilmesini azaltması ya da reseptörlerini doğrudan bloke edilmesi ile ilişkili olabileceği ileri sürülebilir. Ayrıca bu etkinin nosiseptif eşiğin artması ya da ağr1 uyaranının sinir lifine iletiminin engellenmesi ile ilişkili olması da mümkündür (Kasap ve Can 2016).

Çalışma kapsamında benzotiyazol türevlerinin antinosiseptif etkinliğinin yanı sıra anksiyolitik-benzeri etkileri de araştırılmışırı. Anksiyolitik-benzeri etki taramalarında delikli tahta ve yükseltilmiş artı șekilli labirent testleri sıklıkla kullanılmaktadır (Can ve ark. 2012a, Can ve ark. 2012b, Can ve ark. 2013, Can ve ark. 2016). Delikli tahta testinde deney hayvanlarının yeni bir ortamdaki keşif davranışları değerlendirilmektedir (File ve Pellow 1985). Yükseltilmiş artı şekilli labirent testinde ise, deney hayvanları yerden yüksekte olan art1 şekilli labirente konulmaktadırlar. Bu düzenekte deney hayvanları açı, dar ve yüksek olan kollardan kaçınmakta ve doğal eğilimleri gereği kapalı ve karanlık kolları tercih etmektedirler (Kumar ve ark. 2007, Can ve ark. 2016). Anksiyolitik ajanların \%AKGS ve \%AKKS değerlerinde artısa neden olurken, anksiyojeniklerin bu değerleri azalttı̆g bildirilmiştir (Sampath ve ark. 2011). Bu çalışmada, $3 \mathrm{f}, 3 \mathrm{~g}$ ve $3 \mathrm{~h}$ kodlu test bileşikleri farelerin ilk baş daldırma sürelerini kısaltmış, toplam baş daldırma sayılarını ise artırmış̦tır. Ayrıca söz konusu bileşiklerin \%AKGS ve \%AKKS değerlerini artırdığ belirlenmiştir. Bu bulgular, 3f, $3 \mathrm{~g}$ ve $3 \mathrm{~h}$ kodlu bileşiklerin anksiyolitik-benzeri etki gösterdiklerine işaret etmektedir.

Deney hayvanlarının motor koordinasyonlarının değerlendirildiği Rota-rod testlerinde test bileşikleri farelerin dönen milden düşme sürelerinde istatistiksel olarak anlamlı bir değişikliğe neden olmamıştır. Bu bulgu, bu çalışmada ortaya konulan farmakolojik etkilerin spesifik olduğunu göstermektedir.

\section{SONUÇ}

Deneyler sonucunda, $3 \mathrm{f}, 3 \mathrm{~g}$ ve $3 \mathrm{~h}$ kodlu bileşiklerin santral antinosiseptif ve anksiyolitik-benzeri etki gösterdikleri; $3 \mathrm{e}$ kodlu bileşiğin ise periferal antinosiseptif etki gösterdiği saptanmıştır. Bileşiklerin yapıları incelendiğinde, santral etkinlik gösteren $3 \mathrm{f}, 3 \mathrm{~g}$ ve $3 \mathrm{~h}$ kodlu bileşiklerin piperazin halkasının 4 . konumunda fenil ya da benzil sübstitüenti taşıdıkları, periferal etkinlik gösteren $3 \mathrm{e}$ kodlu bileşiğin ise piperazin halkasinin 4 . konumunda dimetilaminoetil sübstitüenti taşıdığ1 görülmektedir. Piperazin halkasının 4. konumunda aromatik yapılar içeren 3f, $3 g$ ve $3 \mathrm{~h}$ kodlu bileşiklerin yüksek $\log \mathrm{P}$ değerlerine sahip oldukları çalışma grubumuz tarafindan daha önce bildirilmiştir (Demir Özkay ve ark. 2017b). Bu 
nedenle, söz konusu bileşiklerin santral etkilerinin lipofilik özellikleri ile ilişkili olduğu ileri sürülebilir.

$\mathrm{Bu}$ çalışmanın bulguları benzotiyazol halkası taşıyan bileşiklerin antinosiseptif ve anksiyolitik-benzeri etkilerini bildiren önceki çalışmaları destekler niteliktedir. Diğer yandan, söz konusu farmakolojik etkilere aracilık eden mekanizmaların aydınlatılması için daha detaylı çalışmalara gereksinim duyulmaktadir.

\section{TEŞEKKÜR}

Bu çalısmanin yazarlar, test maddelerinin teminindeki desteğinden dolayn Prof. Dr. Yusuf ÖZKAY'a ve yapmıs olduğu finansal destekten dolayn Anadolu Üniversitesi Bilimsel Arastorma Projeleri Komisyonu'na (Proje No: 1805S200) teșekekülerini sunar.

\section{KAYNAKLAR}

Ali R, Siddiqui N. New benzo[d]thiazol-2-yl-aminoacetamides as potential anticonvulsants: synthesis, activity and prediction of molecular properties. Arch Pharm (Weinheim). 2015; 348(4):254-265.

Amnerkar ND, Bhusari KP. Synthesis, anticonvulsant activity and 3D-QSAR study of some prop-2-eneamido and 1acetyl-pyrazolin derivatives of aminobenzothiazole. Eur J Med Chem. 2010; 45(1):149-159.

Anzini M, Chelini A, Mancini A, Cappelli A, Frosini M, Ricci L, Valoti M, Magistretti J, Castelli L, Giordani A, Makovec F, Vomero S. Synthesis and biological evaluation of amidine, guanidine, and thiourea derivatives of 2-amino(6-trifluoromethoxy)benzothiazole as neuroprotective agents potentially useful in brain diseases. J Med Chem. 2010; 53(2):734-744.

Aouad MR, Soliman MA, Alharbi MO, Bardaweel SK, Sahu PK, Ali AA, Messali M, Rezki N, Al-Soud YA. Design, Synthesis and anticancer screening of novel benzothiazole-piperazine-1,2,3-triazole hybrids. Molecules. 2018; 23(11): 2788.

Azam MA, Dharanya L, Mehta CC, Sachdeva S. Synthesis and biological evaluation of some novel pyrazolopyrimidines incorporating a benzothiazole ring system. Acta Pharm. 2013; 63(1):19-30.

Can OD, Altintop MD, Ozkay UD, Uçel UI, Doğruer B, Kaplancikli ZA. Synthesis of thiadiazole derivatives bearing hydrazone moieties and evaluation of their pharmacological effects on anxiety, depression, and nociception parameters in mice. Arch Pharm Res. 2012a; 35(4):659-669.

Can OD, Demir Özkay U, Kıyan HT, Demirci B. Psychopharmacological profile of Chamomile (Matricaria recutita L.) essential oil in mice. Phytomedicine. 2012b; 19(3-4):306-310.

Can ÖD, Demir Özkay Ü, Üçel Uİ. Anti-depressant-like effect of vitexin in $\mathrm{BALB} / \mathrm{c}$ mice and evidence for the involvement of monoaminergic mechanisms. Eur J Pharmacol. 2013; 699(1-3):250-257.

Can ÖD, Turan N, Alyu F. 1,3,5-triaril-4,5-dihidro-1h-pirazol türevi bazı bileşiklerin benzodiazepin reseptörleri aracilıklı anksiyolitik-benzeri etkileri. Cukurova Med J. 2016; 41(2):304-315.

Carboni S, Hiver A, Szyndralewiez C, Gaillard P, Gotteland JP, Vitte PA. AS601245 (1,3-benzothiazol-2-yl (2-[[2-(3pyridinyl) ethyl] amino]-4 pyrimidinyl) acetonitrile): a cJun NH2-terminal protein kinase inhibitor with neuroprotective properties. J Pharmacol Exp Ther. 2004; 310(1):25-32

Coelho LP, Reis PA, de Castro FL, Gayer CR, da Silva Lopes C, da Costa e Silva MC, de Carvalho Sabino KC, Todeschini AR, Coelho MG. Antinociceptive properties of ethanolic extract and fractions of Pterodon pubescens Benth. seeds. J Ethnopharmacol. 2005; 98(12):109-116.

Costanzo MJ, Yabut SC, Almond HR Jr, Andrade-Gordon P, Corcoran TW, De Garavilla L, Kauffman JA, Abraham WM, Recacha R, Chattopadhyay D. Potent, small-molecule inhibitors of human mast cell tryptase. Antiasthmatic action of a dipeptide-based transition-state analogue containing a benzothiazole ketone. J Med Chem. 2003; 46(18):3865-3876.

D'Amour FE, Smith DL. A method for determining loss of pain sensation. J Pharmacol Exp Ther. 1941; 72(1):74-79.

Demir Özkay U, Can OD. Anti-nociceptive effect of vitexin mediated by the opioid system in mice. Pharmacol Biochem Behav. 2013; 109:23-30.

Demir Özkay Ü, Can ÖD, Sağlık BN, Turan N. A benzothiazole/piperazine derivative with acetylcholinesterase inhibitory activity: Improvement in streptozotocin-induced cognitive deficits in rats. Pharmacol Rep. 2017a; 69(6):1349-1356.

Demir Özkay Ü, Kaya C, Acar Çevik U, Can ÖD. Synthesis and antidepressant activity profile of some novel benzothiazole derivatives. Molecules. 2017b; 22(9): 1490.

File SE, Pellow S. The effects of triazolobenzodiazepines in two animal tests of anxiety and in the holeboard. $\mathrm{Br} \mathrm{J}$ Pharmacol. 1985; 86(3):729-735.

Gabra BH, Sirois P. Beneficial effect of chronic treatment with the selective bradykinin B1 receptor antagonists, R-715 and R-954, in attenuating streptozotocin-diabetic thermal hyperalgesia in mice. Peptides. 2003; 24(8):1131-1139.

Gökce M, Cakir B, Erol K, Sahin MF. Synthesis and antinociceptive activity of [(2-oxobenzothiazolin-3yl)methyl]-4-alkyl/aryl-1,2,4-triazoline-5-thiones. Arch Pharm (Weinheim). 2001; 334(8-9):279-283.

Hamdy NA, Abdel-Aziz HA, Kamel GM, Fakhr IM. Convenient synthesis, anti-inflammatory, analgesic and ulcerogenic activites of some new bis-hydrazones and pyrazole derivatives. Acta Pol Pharm. 2013; 70(3):469480.

Hassan MZ, Khan SA, Amir M. Design, synthesis and evaluation of $\mathrm{N}$-(substituted benzothiazol-2-yl)amides as anticonvulsant and neuroprotective. Eur J Med Chem. 2012; 58:206-213.

Hroch L, Aitken L, Benek O, Dolezal M, Kuca K, GunnMoore F, Musilek K. Benzothiazoles - scaffold of interest for CNS targeted drugs. Curr Med Chem. 2015; 22(6):730-747.

Kaplancikli ZA, Turan-Zitouni G, Ozdemir A, Can Ov, Chevallet P. Synthesis and antinociceptive activities of some pyrazoline derivatives. Eur J Med Chem. 2009; 44(6):2606-2610.

Karali N, Güzel O, Ozsoy N, Ozbey S, Salman A. Synthesis 
of new spiroindolinones incorporating a benzothiazole moiety as antioxidant agents. Eur J Med Chem. 2010; 45(3):1068-1077.

Kasap M, Can, ÖD. Opioid system mediated anti-nociceptive effect of agomelatine in mice. Life Sci. 2016; 163:55-63.

Keri RS, Quintanova C, Marques SM, Esteves AR, Cardoso SM, Santos MA. Design, synthesis and neuroprotective evaluation of novel tacrine-benzothiazole hybrids as multi-targeted compounds against Alzheimer's disease. Bioorg Med Chem. 2013; 21(15):4559-4569.

Koster R, Anderson M, De Beer EJ. Acetic acid for analgesic screening. Fed Proc. 1959; 18:412-415.

Kumar KV, Krishna DR, Palit G. Histaminergic H1 receptors mediate L-histidine-induced anxiety in elevated plus-maze test in mice. Behav Pharmacol. 2007; 18(3):213-217.

Liu DC, Zhang HJ, Jin CM, Quan ZS. Synthesis and biological evaluation of novel benzothiazole derivatives as potential anticonvulsant agents. Molecules. 2016; 21(3):164.

Mariappan G, Prabhat P, Sutharson L, Banerjee J, Patangia U, Nath S. Synthesis and antidiabetic evaluation of benzothiazole derivatives. J Korean Chem Soc. 2012; $56(2): 251-256$

Moreno-Díaz H, Villalobos-Molina R, Ortiz-Andrade R, Díaz-Coutiño D, Medina-Franco JL, Webster SP, Binnie M, Estrada-Soto S, Ibarra-Barajas M, LeónRivera I, Navarrete-Vázquez G. Antidiabetic activity of N-(6-substituted-1,3-benzothiazol-2-

yl)benzenesulfonamides. Bioorg Med Chem Lett. 2008; 18(9):2871-2877.

Muttu CT, Bhanushali MD, Hipparagi SM, Tikare VP, Karigar A. Microwave assisted synthesis and evaluation of some fluoro chloro 2-N-(substituted Schiffs bases)aminobenzothiazoles derivatives for their antiinflamatory activity. Int J Res Ayurveda Pharm. 2010; 1(2):522-528.

Osmaniye D, Levent S, Karaduman AB, Ilgın S, Özkay Y, Kaplanciklı ZA. Synthesis of new benzothiazole acylhydrazones as anticancer agents. Molecules. 2018; 23(5): 1054 .

Park SH, Sim YB, Kang YJ, Kim SS, Kim CH, Kim SJ, Seo JY, Lim SM, Suh HW. Hop extract produces antinociception by acting on opioid system in mice. Korean J Physiol Pharmacol. 2012; 16(3):187-192.

Pinheiro MM, Boylan F, Fernandes PD. Antinociceptive effect of the Orbignya speciosa Mart. (Babassu) leaves: evidence for the involvement of apigenin. Life Sci. 2012; 91(9-10):293-300

Sampath C, Holbik M, Krenn L, Butterweck V. Anxiolytic effects of fractions obtained from Passiflora incarnata L. in the elevated plus maze in mice. Phytother Res. 2011; 25(6):789-795

Sarkar S, Siddiqui AA, Saha SJ, De R, Mazumder S, Banerjee C, Iqbal MS, Nag S, Adhikari S, Bandyopadhyay U. Antimalarial activity of small-molecule benzothiazole hydrazones. Antimicrob Agents Chemother. 2016; 60(7):4217-4228.

Sasaki-Hamada S, Sacai H, Sugiyama A, Iijima T, Saitoh A, Inagaki M, Yamada M, Oka J. Riluzole does not affect hippocampal synaptic plasticity and spatial memory, which are impaired by diazepam in rats. J Pharmacol Sci. 2013; 122(3):232-236.

Siddiqui N, Rana A, Khan SA, Ahsan W, Alam MS, Ahmed S. Analgesic and antidepressant activities of benzothiazole-benzamides. Biomed Pharmacol J. 2008; 1(2):297-300

Siddiqui N, Rana A, Khan SA, Bhat MA, Haque SE. Synthesis of benzothiazole semicarbazones as novel anticonvulsants-the role of hydrophobic domain. Bioorg Med Chem Lett. 2007; 17(15):4178-4182.

Singh MK, Tilak R, Nath G, Awasthi SK, Agarwal A. Design, synthesis and antimicrobial activity of novel benzothiazole analogs. Eur J Med Chem. 2013; 63:635644

Takeda H, Tsuji M, Matsumiya T. Changes in head-dipping behavior in the hole-board test reflect the anxiogenic and/or anxiolytic state in mice. Eur J Pharmacol. 1998; 350(1):21-29

Thakkar SS, Thakor P, Ray A, Doshi H, Thakkar VR Benzothiazole analogues: Synthesis, characterization, MO calculations with PM6 and DFT, in silico studies and in vitro antimalarial as DHFR inhibitors and antimicrobial activities. Bioorg Med Chem. 2017; 25(20):5396-5406.

Ugwu DI, Okoro UC, Ukoha PO, Gupta A, Okafor SN. Novel anti-inflammatory and analgesic agents: synthesis, molecular docking and in vivo studies. J Enzyme Inhib Med Chem. 2018; 33(1):405-415.

Wang S, Chen Y, Zhao S, Xu X, Liu X, Liu BF, Zhang G. Synthesis and biological evaluation of a series of benzoxazole/benzothiazole-containing 2,3dihydrobenzo[b][1,4]dioxine derivatives as potential antidepressants. Bioorg Med Chem Lett. 2014; 24(7):1766-1770

Wong CH, Dey P, Yarmush J, Wu WH, Zbuzek VK. Nifedipine-induced analgesia after epidural injection in rats. Anesth Analg. 1994; 79(2):303-306.

Woolfe G, MacDonald AD. The evaluation of the analgesic action of pethidine hydrochloride (Demerol). J Pharmacol Exp Ther. 1944; 80(3):300-307.

Zha GF, Leng J, Darshini N, Shubhavathi T, Vivek HK, Asiri AM, Marwani HM, Rakesh KP, Mallesha N, Qin HL. Synthesis, SAR and molecular docking studies of benzo[d]thiazole-hydrazones as potential antibacterial and antifungal agents. Bioorg Med Chem Lett. 2017; 27(14):3148-3155. 